\title{
LEGISLACIÓN POLÍTICO-LINGÜÍSTICA: ANÁLISIS COMPARATIVO DEL DISCURSO DE DOS PLANES DE ESTUDIOS DE PROFESORADO DE INGLÉS
}

\author{
POLITICAL AND LINGUISTIC POLICIES: A COMPARATIVE \\ DISCOURSE ANALYSIS OF TWO ENGLISH TEACHER \\ EDUCATION PROGRAMS
}

\section{Claudia Alejandra Borgnia**}

\section{RESUMEN}

Los planes de estudios de carreras de formación docente en idiomas, además de reflejar distintos tipos de posiciones políticas, pedagógicas y epistemológicas, concretan ideologías y representaciones acerca de las lenguas. Estas pueden ser abordadas a partir del estudio de las políticas lingüísticas desde el seno de la sociología del lenguaje. El propósito del presente trabajo es dilucidar las formas en que dos de los conceptos vinculados a las políticas lingüísticas, i.e., las representaciones sociolingüísticas y las ideologías, operaron en la redacción de los Planes de Estudios del Profesorado de Inglés de 1999 y 2019 en una universidad estatal de la ciudad de Mar del Plata, Argentina. A tal fin, rastreamos el corpus propuesto mediante metodología del análisis del discurso para identificar distintas formaciones subjetivas.

Palabras clave: políticas lingüísticas, representaciones sociolingüísticas, ideologías lingüísticas, planes de estudios, análisis del discurso 
Borgnia, C. A. (2021). Legislación político-lingüística: análisis comparativo del discurso de dos planes de estudios de profesorado de inglés. UCMaule, 67, julio-diciembre, 98-120. DOI: https://doi. org/10.29035/ucmaule.61.98

\section{ABSTRACT}

English Teacher Education Programs reflect different political, pedagogical and epistemological positions, as well as language ideologies. These specific ideologies can be approached through the study of language policies in the field of sociology of language. The purpose of the present work is to explore how sociolinguistic representations and ideologies are embodied in the 1999 and 2019 texts of the English Teacher Education Programs of a state-owned university in Mar del Plata, Argentina. To that end, discourse analysis methodology will be used to identify different subjective stances.

Key words: language policies, sociolinguistic representations, language ideologies, program, discourse analysis.

\section{INTRODUCCIÓN}

Los planes de estudios son proyectos educativos que concretan las posiciones ideológicas, socio-antropológicas, epistemológicas, pedagógicas y psicológicas (Coll, 1991) que determinan los objetivos de la educación en un momento y contexto determinado. En el caso de la redacción de planes de estudios de carreras de formación docente en lenguas, se suma otro factor de peso: las ideologías y representaciones acerca de las lenguas. Estas pueden ser abordadas a partir del estudio de las políticas lingüísticas desde el seno de la sociología del lenguaje, aunque sabemos que otros dominios de la lingüística, también, se ocupan de la relación entre lengua y sociedad, tales como la sociolingüística, la etnografía del habla o de la comunicación.

La política lingüística, "determinación de las grandes opciones en materia de relaciones entre las lenguas y la sociedad y su puesta en práctica, la planificación lingüística, son conceptos recientes que abarcan las antiguas formas de «intervención humana en la lengua»" (Calvet, 1997, p. 2). También se ha definido a la política lingüística como "cursos de acción con relación al uso público de las lenguas fijados por los Estados nacionales o provinciales" (Bein, 2012b, p. 30) y representan formas en que el poder ejerce su dominio sobre la lengua y a la vez, a través de ella. Estas políticas se concretan en lineamientos jurídicos de diverso alcance; las hay nacionales, provinciales, y/o regionales y operan en los contextos más variados: legislación escolar, leyes de radiodifusión, planes de estudios, regulaciones sobre las propagandas, manuales de uso de las lenguas, diccionarios, etc. Aunque formalmente las políticas lingüísticas han sido estudiadas dentro del marco de la sociología del lenguaje a partir del nacimiento de esta disciplina de la mano de Joshua Fishman (1972), podríamos rastrear, 
Borgnia, C. A. (2021). Legislación político-lingüística: análisis comparativo del discurso de dos planes de estudios de profesorado de inglés. UCMaule, 67, julio-diciembre, 98-120. DOI: https://doi. org/10.29035/ucmaule.61.98

retrospectivamente, la relación entre cultura, pueblo, identidad y lengua hasta llegar a los orígenes mismos de la humanidad. Lo que la ciencia lingüística de los últimos años nos ha brindado es una serie de herramientas para estudiar dichos fenómenos.

El propósito del presente trabajo es dilucidar las formas en que dos de los conceptos vinculados a las políticas lingüísticas, i.e., las representaciones sociolingüísticas y las ideologías, operaron en la redacción de los Planes de Estudios del Profesorado de Inglés de la Universidad Nacional de Mar del Plata (desde ahora UNMDP) del año 1999 y del 2019. A tal fin, realizaremos un recorrido histórico del Profesorado de Inglés y de la legislación lingüística pertinente para luego rastrear el corpus propuesto mediante metodología del análisis del discurso con el objetivo de identificar las formaciones subjetivas que operaron en relación a las categorías de 1) perfil del hablante/docente de inglés; 2) ideología lingüística, función del inglés y oferta de lenguas extranjeras; 3) sintagmas que denominan materias culturales. La investigación estará encuadrada teóricamente dentro de la sociología del lenguaje, ya que como apuntábamos anteriormente, esta disciplina se ocupa de estudiar las relaciones entre lenguas, variedades, Estados, pueblos y naciones y la forma en que estas transacciones se transforman para pautar o normar los usos públicos de las lenguas. Nuestro aporte a la sociología del lenguaje radica en el potencial para vincular estructura social y conducta lingüística con respecto al inglés como lengua extranjera en Argentina y para desmontar los mecanismos ideológicos que operaron en distintos dispositivos de legislación escolar nacional y provincial, y a su vez como éstos ejercieron su influencia en los planes de estudios de una carrera de formación docente en inglés. A la fecha, no hemos encontrado otro trabajo que aborde específicamente la comparación de dos planes de estudios de profesorados de inglés con la mirada puesta en las ideologías y representaciones sociolingüísticas en Argentina. En las líneas que siguen trataremos de explorar de qué manera el contexto socio-político de la EGB ha incidido en la redacción de los documentos estudiados.

\section{Orígenes del Profesorado de Inglés de la UNMDP}

Según consta en ambos planes de estudios, el Profesorado de Inglés de la UNMDP nació, inicialmente, como fruto de la fusión de los Profesorados de Inglés ofrecidos por el IMES, Instituto Municipal en Estudios Superiores, y la Universidad Católica de Mar del Plata. En 1975, se crea un departamento, el de Lenguas Modernas, perteneciente a la Facultad de Humanidades, al cual sigue perteneciendo la carrera hasta el momento. 
Borgnia, C. A. (2021). Legislación político-lingüística: análisis comparativo del discurso de dos planes de estudios de profesorado de inglés. UCMaule, 67, julio-diciembre, 98-120. DOI: https://doi. org/10.29035/ucmaule.61.98

Al momento de su creación, el profesorado suplía las demandas de formación de profesores en lengua inglesa para abastecer al Laboratorio de Idiomas de la misma universidad, colegios privados, escuelas secundarias estatales, institutos privados de inglés, emprendimientos turísticos, empresas diversas y grupos de profesionales. El Laboratorio de Idiomas ofrecía, en ese momento, cursos de extensión en idioma alemán, francés, portugués, inglés e italiano. La creación de este laboratorio evidenció la necesidad de tener docentes universitarios capacitados para dictar clases, especialmente de idioma inglés. Muchos de sus docentes no poseían titulación y, a partir de un estudio de marketing realizado por las escuelas secundarias, se determinó el interés por la carrera de Profesorado de Inglés. Lo que no queda claro, desde la documentación que recoge la historia del profesorado, son los motivos por los que el Departamento de Lenguas Modernas no ofrecía oportunidades de formación universitaria para profesionales que enseñaban los otros idiomas enseñados en el Laboratorio: alemán, italiano, francés y portugués.

\section{Motivos subyacentes a la hegemonía del inglés como lengua extranjera: de lo local a lo nacional}

La duda anterior nos obliga a investigar los motivos por los cuales el Departamento de Lenguas Modernas, en el que — hasta la fecha- se ofrece solo una carrera de grado: el Profesorado de Inglés, no ofrece además formación docente en otros idiomas. En numerosas publicaciones Roberto Bein por su parte (2004, 2012a, 2012b) y Arnoux \& Bein (2015) advierten sobre los condicionamientos a partir de las cuales, hoy en día, el inglés es el idioma más usado por la población argentina como lengua extranjera o adicional, y ésto está estrechamente relacionado con el hecho de que, en la actualidad, el inglés es considerado como la lengua franca mayormente empleada en el mundo. Tal vez, a raíz de esto, el inglés es la lengua extranjera privilegiada en el sistema escolar estatal y privado y en otras instituciones de enseñanza de idiomas en todo el país. A pesar de que, según la Dirección Nacional de Migraciones en 1970 (citado en Bein, 2012a), los inmigrantes británicos representaban el 1,1\% de la población argentina total en el período 1857-1940, muy por detrás de las cifras de aquellos provenientes de Italia, España y Francia, que mostraban porcentajes mucho más altos, con el 44,9, 31,5 y 3,6 \% respectivamente, ya desde mediados del siglo XX, el inglés comenzó a ganar espacio como una de las lenguas extranjeras preponderantes en la legislación escolar oficial, finalmente desplazando al francés. 
Borgnia, C. A. (2021). Legislación político-lingüística: análisis comparativo del discurso de dos planes de estudios de profesorado de inglés. UCMaule, 67, julio-diciembre, 98-120. DOI: https://doi. org/10.29035/ucmaule.61.98

De todas formas, el número de inmigrantes de las diferentes olas inmigratorias, por sí mismo, no es suficiente para explicar la primacía del inglés. Si nos guiamos por el número de los inmigrantes con mayor afluencia inmigratoria en nuestro país, la lengua extranjera, por excelencia, debería ser el italiano. Otro hecho que pone de manifiesto la posición hegemónica del inglés por sobre las otras lenguas extranjeras es la distribución de profesorados de idiomas ofrecidos por universidades nacionales en la República Argentina. En el Gráfico 1 se presentan los profesorados de lenguas extranjeras en el país, teniendo en cuenta los datos obtenidos de sitios web de cada universidad. En la actualidad, existen 29 carreras de profesorado de idiomas universitarios en el ámbito nacional. Dieciséis de estas casas de altos estudios forman docentes en lengua inglesa, 6 ofrecen formación en francés, 5 en portugués, y 1 en alemán e italiano, respectivamente.

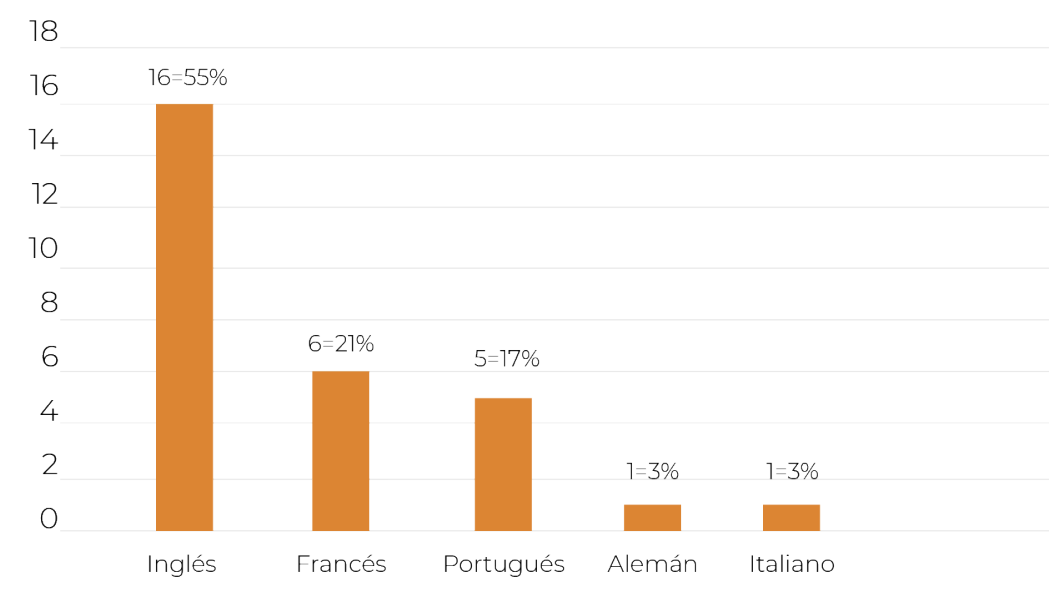

Gráfico 1: Profesorados de Lenguas Extranjeras ofrecidos en Universidades Nacionales Argentinos en 2021

El Gráfico 2 muestra los profesorados de lenguas extranjeras en institutos terciarios. En este contexto, las disparidades son aún más pronunciadas que en el caso anterior. De los 222 profesorados, 193 se corresponden con la enseñanza de inglés, 13 con la de francés, 1 con la del alemán, 4 con italiano y 11 con portugués. Estas cifras ponen de manifiesto, aún con más claridad, que el inglés es la lengua extranjera mayormente enseñada en nuestro país. En las secciones subsiguientes, se explicarán los motivos que conllevan esta situación. 
Borgnia, C. A. (2021). Legislación político-lingüística: análisis comparativo del discurso de dos planes de estudios de profesorado de inglés. UCMaule, 67, julio-diciembre, 98-120. DOI: https://doi. org/10.29035/ucmaule.61.98

Gráfico 2: Profesorados de Lenguas Extranjeras ofrecidos en Institutos de formación docente terciarios en Argentina en 2017.

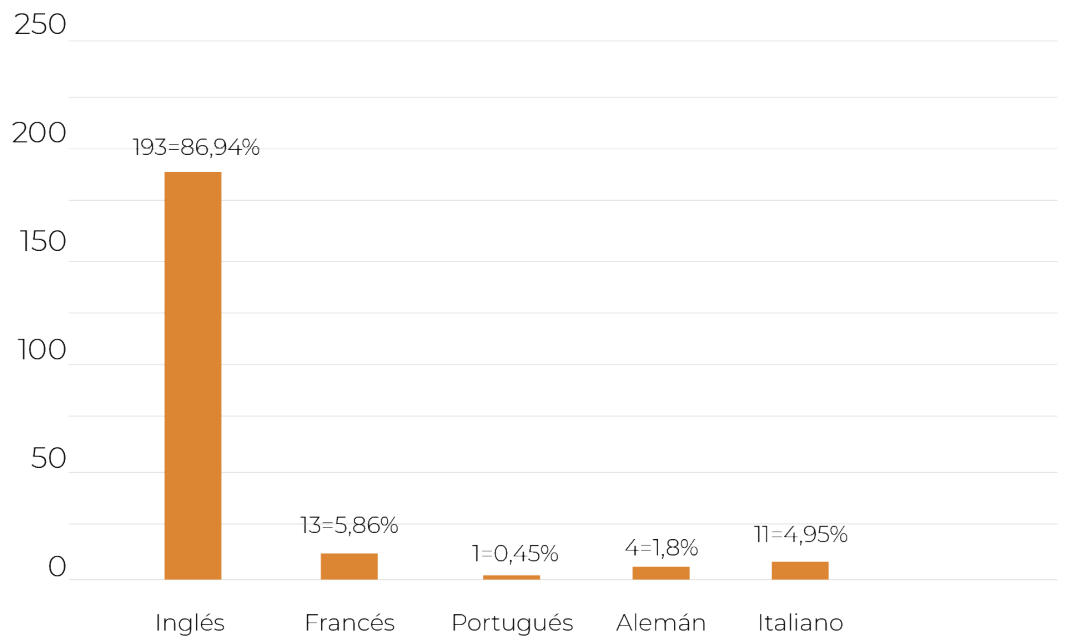

Nota: Datos obtenidos del Estudio de Montserrat y Motorola (2018).

\section{Política Lingüística: Legislación Lingüística Escolar}

Podemos rastrear los orígenes de las políticas lingüísticas contemporáneas a partir de la emergencia del Estado-Nación en Argentina, en el siglo XIX. Hacia fines de este siglo, las diferentes olas migratorias de origen europeo se asentaron y, con el proyecto de crear una nación europea en Latinoamérica, se instauró de hecho el español como lengua oficial. La intención era sementar la identidad argentina y que el uso del castellano puro borrara todas las marcas de las lenguas de los nuevos pobladores. A través de las escuelas y de la conscripción militar, se logró concretar, con algunas excepciones, el proyecto de una nación monolingüe para comienzos del siglo xx (Bein, 2012a, Arnoux \& Bein, 2015). Durante los primeros años del siglo XX, creció la población ante la llegada de nuevas olas inmigratorias. El crecimiento poblacional, junto con la consolidación de una pujante clase media visibilizó mayores demandas educativas que trascendían la formación ofrecida en la escuela primaria. Así, se evidenció la necesidad de formar docentes en todas las materias, incluidas las lenguas extranjeras, para abastecer las nuevas necesidades de un país emergente. 
Borgnia, C. A. (2021). Legislación político-lingüística: análisis comparativo del discurso de dos planes de estudios de profesorado de inglés. UCMaule, 67, julio-diciembre, 98-120. DOI: https://doi. org/10.29035/ucmaule.61.98

A raíz de esta creciente demanda, a principios del siglo XX, se crearon los Institutos de Profesorado de Lenguas Vivas y el Instituto Nacional Superior del Profesorado (1904). De a poco, el inglés, francés, alemán e italiano, junto a las lenguas clásicas, comenzaron a mostrar un crecimiento en la currícula escolar. El ideal de europeo latinoamericano (Bein, 2012, Arnoux \& Bein, 2015) seguía vigente a pesar de la castellanización exitosa y exigía el conocimiento de otras lenguas europeas, especialmente para acceder al consumo de los bienes culturales (Bourdieu, 1997) de las elites y de la nueva clase media.

El primer hito en materia de políticas lingüísticas, luego del proceso de castellanización, fue la reforma del año 1942. En ese año, bajo los auspicios del presidente Castillo, se publicó un decreto de reforma de los planes de estudios de las escuelas oficiales mediante el cual se suprimió la simultaneidad de estudios de lenguas extranjeras por supuestos motivos pedagógicos. Esto significaba que los estudiantes podían tomar clases de idiomas, pero combinados de tal forma que no era posible cursar solo lenguas románicas; siempre el inglés debía ser parte de las combinaciones de idiomas estudiados. En resumen, este decreto, que estaba justificado por razones de "solidaridad continental2" hacia los Estados Unidos y por la creencia de que aprender una lengua romance y una sajona era beneficioso, privilegiaba la enseñanza escolar del inglés frente a las otras lenguas. A partir de este momento, el inglés continuó siendo siempre la lengua extranjera hegemónica en el sistema escolar. Debemos aclarar, en este punto, que el alemán, que se había enseñado en algunos colegios privados durante el siglo XIX y en colegios técnicos en el siglo xx, perdió espacio en currículo escolar debido a las simpatías antifascistas ${ }^{3}$ de algunos funcionarios del gobierno al finalizar la Segunda Guerra Mundial (Bein, 2012) y a la fuerza del inglés.

La supremacía del inglés se vio favorecida nuevamente cuando, por resolución ministerial 1813 de 1988, se legisló que ya no era posible estudiar más que una única lengua extranjera durante el trayecto académico del período de educación secundaria. Por omisiones en la resolución, quedó al azar la elección de la lengua que debía estudiarse. Entre las opciones estaban el inglés, el francés y el italiano. La elección de la lengua ofrecida, en cada caso, quedaba en manos de los directores de las instituciones. Esto significa que la resolución dejaba un vacío legal. Ante las alternativas, un gran porcentaje de directivos optó por la lengua de supremacía social en el momento: el inglés. Claramente, concluimos que las omisiones mencionadas no fueron inocentes

2 Las "relaciones carnales" no hacen más que remitir a las transacciones económicas y culturales con los Estados Unidos, con lo cual, la "solidaridad continental" con el país del norte prevalece frente a aquellas que podrían entablarse con países latinoamericanos.

3 Son sugerentes los motivos por los que la enseñanza del italiano no fue suprimida de manera similar. 
Borgnia, C. A. (2021). Legislación político-lingüística: análisis comparativo del discurso de dos planes de estudios de profesorado de inglés. UCMaule, 67, julio-diciembre, 98-120. DOI: https://doi. org/10.29035/ucmaule.61.98

y que, más bien en ese caso, la política lingüística operó implícitamente reforzando, desde una falsa libertad de elección, la opción más favorecida.

Otra política lingüística que continuó acentuando la preeminencia del inglés fue el Acuerdo-Marco Nº 15 para la Enseñanza de Lenguas, el cual fue aprobado por el Consejo Federal de Cultura y Educación en 1998. Mediante este acuerdo, todas las jurisdicciones se comprometían a la inclusión progresiva de la enseñanza de lenguas extranjeras en la escolaridad obligatoria, que había sido extendida al $9^{\circ}$ año de Educación General Básica. El acuerdo sugería el comienzo de la educación en lengua extranjera a partir de 4to año de la escuela primaria (Bein, 2012b). En los próximos años, a pesar de no haber legislación lingüística nacional visible, el prestigio del inglés se acrecentó aún más, debido al predominio económico de los Estados Unidos, la globalización, los acuerdos comerciales, el uso extendido de internet y otros tantos recursos tecnológicos.

En 2006 se aprobó la Ley de Educación Nacional. Esta proclamaba la restitución de los derechos de los aborígenes para que accedieran a hablar su propia lengua a la vez que apoyaba la multiculturalidad y el derecho a los estudiantes a aprender distintas lenguas extranjeras. Al igual que en el pasado, el derecho a aprender las distintas lenguas extranjeras se reducía, en lo concreto, a aprender inglés. La nueva ley sugería la adopción de una Educación Intercultural Bilingüe en relación a las lenguas aborígenes, ya que sería beneficiosa para todos los estudiantes (Bein, 2012b, Arnoux \& Bein, 2015). También, ponía de manifiesto la importancia de estrechar lazos con los vecinos luso-hablantes mediante la enseñanza del portugués para fortalecer las relaciones comerciales con el Mercosur. De hecho, en 2005, Brasil estableció la enseñanza del español como lengua obligatoria en el sistema escolar, la cual debía instrumentarse a partir de 2010. En Argentina, en 2009, se aprobó una ley análoga que normaba la instauración del portugués como lengua extranjera obligatoria en todo el territorio nacional. En esencia, la Ley Nacional de Educación no logró concretar los cambios en materia de políticas lingüísticas sugeridas. Los proyectos de la multiculturalidad, de la Educación Intercultural Bilingüe, y del portugués como lengua escolar obligatoria han sido concretados en el sistema escolar de manera polarizada, mas no uniformemente.

\section{Representaciones lingüísticas, ideología, fetiche lingüístico y más}

Las ideologías y representaciones lingüísticas o sociolingüísticas ayudan a entender las actitudes hacia las lenguas y las razones por las que las políticas lingüísticas se concretan o solo quedan plasmadas en el texto de la legislación, sin llegar a incidir en el comportamiento lingüístico de una comunidad (Ninyoles, 1972) y ahí radica su importancia en la discusión acerca del estatus de la enseñanza del inglés en 
Borgnia, C. A. (2021). Legislación político-lingüística: análisis comparativo del discurso de dos planes de estudios de profesorado de inglés. UCMaule, 67, julio-diciembre, 98-120. DOI: https://doi. org/10.29035/ucmaule.61.98

Argentina. Según se recoge en los Cuadernos de Glotopolítica 2 (Arnoux, 2000), las representaciones son:

Una suerte de pantalla ideológica que como una lente que distorsiona la visión—se "interpone" entre las prácticas lingüísticas reales y la conciencia social de esas prácticas. Es decir: la sociedad puede tener una conciencia distorsionada de su uso real del lenguaje. Las representaciones tienen materialidad discursiva: están formadas por discursos circulantes en la sociedad, e igual que en el caso de la ideología, puede haber discursos y contradiscursos. (p. 44)

Estas representaciones, según Ninyoles, no tienen asiento en la realidad, sino que son imágenes o percepciones que tienen los individuos con respecto a las lenguas. Bein (2015) retoma la idea de las representaciones como "constructos ideológicos interpuestos entre la praxis lingüística real y la conciencia social de esa praxis" (p.2), resaltando su materialidad tanto discursiva como ideológica. Ya Arnoux y Bein (2015) se referían a las representaciones como "no solo esquemas orientadores socialmente compartidos de la percepción y evaluación de los distintos fenómenos lingüísticos, sino también como diseños más o menos complejos del universo social que los discursos sobre el lenguaje construyen" (p. 9). Según la literatura analizada, estos esquemas socialmente construidos, validados y difundidos, conllevan una evaluación de las prácticas lingüísticas.

El carácter evaluativo de las representaciones se manifiesta en el tipo de expresiones que se utilizan para hacer referencia a las lenguas. Por ejemplo, algunas de las representaciones que suelen circular con respecto a las lenguas son la utilidad, el prestigio, la dificultad o facilidad para aprenderlas, lo feas o lindas que son, lo mal o bien que suenan, o etiquetas tales como que las lenguas tienen propiedades mágicas para conseguir trabajo o regresar a un pasado comunitario añorado. Claramente podemos notar los matices valorativos que emergen de ellas.

En el caso del inglés en Argentina, las representaciones han sido en general positivas y están asociadas a la cualidad de conseguir trabajo, de sonar europeo y culto, de acceder a un estatus social superior. Todos recordaremos haber escuchado afirmaciones tales como "sabiendo inglés se te abren todas las puertas", o "el inglés te abre ventanas al mundo". Ciertamente, las representaciones que circulan en la sociedad argentina acerca del prestigio del inglés han influido en las políticas lingüísticas volcadas en la legislación escolar. El acatamiento de esas leyes está, a su vez, condicionado por esas mismas representaciones, que así se perpetúan hasta que, en algún momento, un contradiscurso alcance un alto nivel de credibilidad y las alternativas que, en el presente 
Borgnia, C. A. (2021). Legislación político-lingüística: análisis comparativo del discurso de dos planes de estudios de profesorado de inglés. UCMaule, 67, julio-diciembre, 98-120. DOI: https://doi. org/10.29035/ucmaule.61.98

no son elegidas comunitariamente a pesar de estar legitimadas por la legislación, logren ser más populares.

En especial, en el artículo "Argentinos: esencialmente europeos..." (2012), Bein realiza una semblanza de las motivaciones que a su entender esclarecen la situación de las lenguas extranjeras en la actualidad en Argentina. Bein vincula la popularidad del inglés como lengua extranjera por excelencia con las representaciones lingüísticas del inglés antes mencionadas y con el hecho de que los argentinos se siguen sintiendo "esencialmente europeos". El aprendizaje de portugués, sin embargo, no satisface el ideario de europeidad, tal vez, porque no está directamente asociado a la imagen de un europeo de origen anglosajón. A través del concepto acuñado como "fetiche lingüístico", el teórico llena el vacío teórico existente en la disciplina: las representaciones sociolingüísticas no explican completamente la idea de que teniendo conocimientos de inglés se consigue trabajo. Así, el fetiche sobrepasa los atributos concretos de la lengua y opera, entonces, otorgándole al inglés cualidades mágicas esenciales.

Dado que no hemos encontrado en la literatura revisada una categoría que haga referencia directa a los hablantes de las lenguas, propondremos aquí el concepto de representaciones lingüísticas acerca de los hablantes para designar las representaciones respecto de las personas o comunidades que hablan una determinada lengua, las cuales operan sobre la base de los estereotipos culturales. En Argentina, tradicionalmente, los hablantes de inglés eran originarios de Gran Bretaña. Luego de las invasiones inglesas, un número de británicos derrotados se amalgamó a la ya existente comunidad británica en el Río de la Plata. Paulatinamente, dadas las relaciones comerciales con Inglaterra, las persecuciones religiosas y políticas en las Islas Británicas, arribaron más inmigrantes angloparlantes de origen inglés, galés, escoces e irlandés.

Luego de las guerras mundiales, la supremacía económica de Gran Bretaña dio lugar a la de los Estados Unidos y, a partir de ese momento, se consolidaron relaciones comerciales con los estadounidenses, lo que conllevó la llegada de un cierto número de inmigrantes de ese país. Desde la perspectiva de los locales, los británicos y luego los estadounidenses, representaban el ideal de europeidad y civilización: orden, respeto por las reglas, afición al trabajo y disciplina. Los primeros profesores de lengua inglesa fueron, indudablemente, los inmigrantes ingleses y/o sus descendientes. También, se contrataban profesores nativos especialmente para dar clases en los colegios bilingües. Estos grupos de nativos, sin conocimiento de pedagogía, por el solo hecho de conocer la lengua y la cultura, se consideraban aptos para enseñarla. Claramente, había una alta demanda de docentes de inglés y, además, el desarrollo en enseñanza de lenguas era nulo o inexistente en esos tiempos. Con el transcurso de los años, en 1904, se crea 
Borgnia, C. A. (2021). Legislación político-lingüística: análisis comparativo del discurso de dos planes de estudios de profesorado de inglés. UCMaule, 67, julio-diciembre, 98-120. DOI: https://doi. org/10.29035/ucmaule.61.98

el primer Profesorado en Inglés en el hoy Instituto de Enseñanza Superior en Lenguas Vivas Juan Ramón Fernández y más adelante, en otros.

Posteriormente, viajeros angloparlantes, egresados de los colegios bilingües, y/o descendientes de los inmigrantes británicos o estadounidenses ayudaron a suplir la marcada demanda de profesores de inglés. Así nacieron las representaciones lingüísticas de los profesores de inglés como personas de éxito y como modelos de corrección lingüística. Dichas representaciones, aunque más difusas, perduran en cierta medida en la actualidad, reforzadas por una gran cantidad de empresas, instituciones educativas y público en general, que continúa solicitando clases de inglés dictadas por nativos.

Las ideologías lingüísticas, otro concepto que, al igual que el de las representaciones, es relativamente nuevo dentro de la lingüística, pueden definirse como "conjuntos de representaciones lingüísticas compartidos en una sociedad y período dados" (Bein, 2012b, p. 30) que tienen el potencial de generar actitudes comunitarias hacia las lenguas. Dado que las ideologías adquieren fuerza normativa al circular dentro de grupos de poder, el grado de ajuste o rechazo a ellas conlleva la pertenencia a tal o cual grupo social (Arnoux y del Valle, 2010). En su trabajo, Arnoux y del Valle definen las ideologías y luego las ilustran con ejemplos de ideologías que operan en Argentina. Mencionan el panhispanismo, como la valoración del español como lengua de unificación entre los países americanos hispanoparlantes y que se refuerza desde el poder central de la "madre patria": España4. El monolingüismo es otro ejemplo de ideología lingüística; constituye el rechazo por el uso de cualquier lengua que no sea la oficial. Por el contrario, el multilingüismo apoya la existencia de diversas lenguas conviviendo en un territorio en igualdad de condiciones. Otro ejemplo es la ideología latinoamericanista (Arnoux y del Valle), similar a la panhispanista, pero ya sin la tutela de España. En oposición a posturas que proclaman una valoración positiva hacia el inglés global, la lengua franca mundial o la lengua franca internacional, una ideología que circula con bastante fuerza entre los contradiscursos es la del anglocentrismo dominante (Cazorla, 2018). Apela a las asociaciones de inglés con la lengua del imperio, la que tiene el poder de sustituir y hasta de eliminar lenguas minoritarias y locales, tal como lo afirma Phillipson (2009) con los sintagmas "lingüicismo" y Price (1984) "lengua genocida" (mi traducción de killer language). Al analizar los discursos de los dos planes de estudios retomaremos el tratamiento de las representaciones, fetiches e ideologías.

$4 \quad$ Como lo explican Arnoux y del Valle, para naturalizar las representaciones sociolingüísticas y que se imponga lo que ellos llaman ideologema partiendo del concepto de Marc Angenot (1982), se recurre a "representaciones emocionales". 
Borgnia, C. A. (2021). Legislación político-lingüística: análisis comparativo del discurso de dos planes de estudios de profesorado de inglés. UCMaule, 67, julio-diciembre, 98-120. DOI: https://doi. org/10.29035/ucmaule.61.98

\section{Metodología}

Abordaremos los documentos desde la perspectiva del análisis del discurso. Adherimos a la visión de análisis del discurso de Arnoux (2006), quién lo concibe por un lado como un campo interdisciplinario, en este caso, lindante entre el discurso educativo y el legal, y por otro, desde la perspectiva interpretativa. Según esta perspectiva, que Arnoux toma de Michel Pecheux (1984), el análisis del discurso se propone develar a través de ciertos procedimientos, aquello que ha sido codificado estratégicamente por un sujeto y que expone el juego dialógico entre lo que se dice, lo que se oculta y lo que de hecho se hace. El procedimiento apuntado por Arnoux (2006) consiste en "exponer las huellas del ejercicio del lenguaje por parte de los sujetos" (p. 21) mediante la selección de indicios reveladores de alguna regularidad significativa. Así se rastrean las variables que pueden haber intervenido en la selección de ciertas opciones lingüísticas y la omisión de otras. Resulta relevante aquí mencionar que en este estudio analizamos dos textos del mismo género, emanados de la misma institución, y que un número de sujetos ha participado en la redacción de ambos documentos, mientras que otros son distintos. Esto significa que han operado diferentes tipos y niveles de condicionantes en la producción del corpus primario.

La indagación llevada a cabo en este trabajo ha constado de los siguientes pasos. Se confrontaron repetidamente ambos documentos primarios, junto a los documentos secundarios, es decir, la legislación escolar nacional y provincial, la reglamentación de la universidad y de la facultad en cuestión. Las distintas lecturas de los documentos se intercalaron con entradas a literatura previa afín realizada en el país (Bein y Varela, 2005) y a las herramientas teóricas de las representaciones e ideologías socio-lingüísticas. Se realizó un análisis del contenido, es decir, la estructura, nombres y cantidad de las asignaturas, distribución del tiempo, contenidos y fundamentación de ambos diseños curriculares. Luego, se registraron los elementos que nos permitieran realizar inferencias con respecto a las formaciones ideológicas, y se volcaron en distintas tablas, que detallaremos en el apartado correspondiente al análisis contrastivo discursivo.

\section{Los planes de estudios 1999 y 2019}

Describiremos brevemente ambos planes de estudios, que son consecutivos, para luego realizar el análisis comparativo. Aclaramos aquí que aún está vigente el Plan 1999, y se estima que el nuevo Plan 2019 se comenzará a implementar en 2023. El Plan de Estudios de 1999 nace como respuesta a las crecientes necesidades de formación de docentes luego de la aprobación de la Ley Federal de Educación (1993), la cual pauta la 
Borgnia, C. A. (2021). Legislación político-lingüística: análisis comparativo del discurso de dos planes de estudios de profesorado de inglés. UCMaule, 67, julio-diciembre, 98-120. DOI: https://doi. org/10.29035/ucmaule.61.98

obligatoriedad del cursado hasta $9^{\circ}$ año y divide la escolaridad en ciclos denominados: inicial, EGB1, EGB2 y EGB3 y la Educación Polimodal. Se le confiere al Consejo de Cultura y Educación la tarea de legislar en el terreno de las lenguas extranjeras y, así, es que el Consejo fijó 9 años de lenguas extranjeras, de los cuales -al menos 3- debían ser de inglés.

Debido a esta división y, al hecho de que la carrera tenía una duración de 4 años, pero había un gran índice de deserción por la oferta horaria y lo poco flexible que es el plan, se extendieron dos títulos extendidos: el de Profesor de Inglés para Nivel Inicial y Primero y Segundo Ciclo de la EGB y el de Profesor Superior de Inglés para Tercer Ciclo de la EGB y la Educación Polimodal. Los dos títulos se expidieron hasta el año 2012, en que la denominación de los ciclos de la escolarización cambió como respuesta a la Ley de Educación Nacional (2006). En ese entonces, la Facultad suspendió el título intermedio para evitar que perdiera validez nacional (OCAS No 3043/2011 y 0803/13) y hasta la fecha se sigue ofreciendo solo el título completo.

El Plan de Estudios de 1999 comprende 32 materias cuatrimestrales, una de las cuales es opcional, distribuidas en 4 años. El número total de horas es de 3.584. Al ingreso, los estudiantes deben rendir dos exámenes de aptitud en el idioma: INI (Idioma Inglés Intermedio) e INA (Idioma Inglés Avanzado). Los estudiantes que aprueban estos exámenes pueden cursar las materias subsiguientes en el plan de estudios. Quienes desaprueban estos exámenes deben cursar dos asignaturas, una por cada nivel, que llevan el mismo nombre de los exámenes. Es decir, que la universidad brinda, a quienes no poseen el nivel adecuado de inglés, la oportunidad de alcanzarlo de manera gratuita. Esta ha sido una medida inclusiva concretada con la implementación del Plan 1999. Mientras estuvo en vigencia el Plan 1989, quienes rendían los exámenes de INI e INA y no los aprobaban, debían procurarse, por medios propios, el nivel requerido. Esta política inclusiva ha ayudado a cambiar el perfil socioeconómico de los ingresantes, ya que en el pasado, los estudiantes que no contaban con el nivel de competencias lingüísticas en inglés requerido y no disponían de recursos económicos para obtenerlo de forma privada, quedaban excluidos.

Mediante el Plan de Estudios 2019, a su vez, se ofrece una carrera también de 4 años y con 32 materias, de las cuales 4 son opcionales y se ofrecen a partir del tercer año. El plan cubre un total de 3104 horas, más 64 horas destinadas a Prácticas Socio Comunitarias. Una de las mayores diferencias entre ambos planes es la duración de la carrera. Mientras que el Plan 2019 tiene 3232 horas, e incluye Prácticas Socio Comunitarias, el Plan 1999 ofrece 3584 horas, y no prevé dicha espacio de prácticas. Otro de los grandes cambios en correspondencia con el proyecto de inclusión de la universidad consiste en la asignación de un mayor número de horas de clase a las materias INI e INA. Dicha asig- 
Borgnia, C. A. (2021). Legislación político-lingüística: análisis comparativo del discurso de dos planes de estudios de profesorado de inglés. UCMaule, 67, julio-diciembre, 98-120. DOI: https://doi. org/10.29035/ucmaule.61.98

nación de horas fortalece el nivel de ingreso del estudiantado, garantizando igualdad de condiciones a toda la población.

El plan está en consonancia con la normativa nacional antes mencionada y con otros lineamientos provinciales. Además, refleja los "Lineamientos Generales de la Formación Docente Comunes a los Profesorados Universitarios" (2012) del Consejo Interuniversitario Nacional y los "Lineamientos Preliminares para los Profesorados en Lenguas Extranjeras" (2018) de la Asociación Nacional de Facultades de Humanidadesy Ciencias de la Educación (ANFHE). En el plano local, el plan responde a "la expresión de su compromiso con el respeto a los derechos humanos y la dinamización de procesos de inclusión y democratización" delineados en el Estatuto de la Universidad. También, adhiere a la reglamentación respecto de la protección de los derechos de personas con discapacidad, del colectivo LGBTI y de las mujeres. Particularmente, los lineamientos de la ANFHE y del CIN son los que dieron lugar al acortamiento de la carrera, ya que de estas entidades surgieron acuerdos para ofrecer una cantidad similar de horas de clase en todos los profesorados universitarios de lenguas y de otras disciplinas en el país.

\section{Análisis contrastivo discursivo de los planes de estudios 1999 y 2019}

Procederemos aquí a analizar el corpus primario utilizando elementos del análisis contrastivo del discurso para dilucidar los posicionamientos socioculturales que intervinieron en la redacción de los planes de estudios. Este diseño metodológico contrastivo nos permite reconocer, delimitar y enfrentar formaciones y prácticas discursivas y posicionamientos ideológicos a través de las siguientes categorías de análisis: 1) perfil del hablante/docente de inglés; 2) ideología lingüística, funciones del inglés y oferta de lenguas extranjeras; 3) sintagmas utilizados para denominar las materias culturales. Consideramos que estas categorías tienen un alto valor explicativo debido a su articulación con las herramientas teóricas provenientes de las ciencias del lenguaje y de la legislación lingüística hasta aquí utilizadas. Como toda categorización del espectro sociolingüístico, corre el riesgo de ser artificial, arbitraria y de no reflejar fehacientemente la compleja trama de relaciones que confluyen en el estudio del comportamiento lingüístico público y las pautas políticas que se proponen normalizarlo.

Por motivos de claridad, hemos decidido resumir los elementos discursivos extraídos de los planes que corresponden a cada categoría en un cuadro comparativo a continuación de su explicación. Debemos aclarar, asimismo, que las construcciones discursivas correspondientes al Plan 2019 registradas en las tablas son mucho más numerosas que las del Plan 1999. Esto puede estar relacionado con la extensión dispar de los documentos (25 páginas el Plan 1999 y 41 el Plan 2019) y también con su naturaleza. 
Borgnia, C. A. (2021). Legislación político-lingüística: análisis comparativo del discurso de dos planes de estudios de profesorado de inglés. UCMaule, 67, julio-diciembre, 98-120. DOI: https://doi. org/10.29035/ucmaule.61.98

\section{Categoría de Análisis 7: Perfil de Docente y/o Hablante de Inglés como Lengua Extranjera.}

La Tabla 1 recoge los indicios que nos permitieron entrever el perfil de docente como hablante de la lengua en ambos documentos. Notamos, por un lado, que en el Plan 1999 siguen vigentes los estereotipos de profesor de inglés que mencionábamos en el apartado acerca de las representaciones sociolingüísticas y el fetiche. Se menciona el "elevado manejo" del idioma del docente ya que oficiará como "modelo" de corrección lingüística, lo cual denota, a la vez, un marcado purismo. Por otro lado, emergen, con cierta timidez, rasgos de un hablante que más que tener una "sólida" competencia lingüística en la lengua meta, tiene que comunicarse adecuadamente, lo cual nos hace pensar en un tipo de hablante que debe poseer otro atributo: la comprensibilidad. Según el Plan 1999, el futuro docente tendrá también un rol como mediador social, será empático y deberá administrar recursos tecnológicos.

Tabla 1: Resumen comparativo del perfil de docente/hablante de inglés en Planes de Estudios 1990 y 2019.

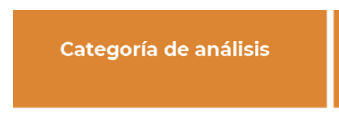

Perfil de docente $y / 0$ hablante de inglés como lengua extranjera

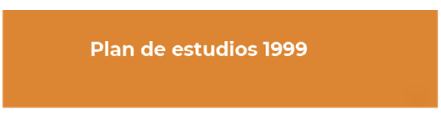

1. Manejo fluido y adecuado del inglés. 2. Elevado nivel de competencia en las cuatro habilidades lingüisticas que le permiten actuar como modelo en el aula.

3. Conocimiento del inglés como medio para acceder a contenidos y como fir. 4. Sólido mancjo tcórico práctico del idioma que va a ensenar 5. Competencia cultural que permita comparar con cultura local y promover la empatía. 6. Dominio fluido del idioma a nivel de comunicación oral y escrita en una variedad de usos, situaciones, regustros, géneros y tipos discursivos.

7. Reconocimiento de variedades dialectales y sociales del idioma inglés.

8. Utilización de herramientas informáticas como recurso para la enseñanza, la actualización y la interacción y socialización profesional.

9. Docentes conscientes de su rol en la sociedad y con capacidad para un continuo desarrollo profesional.

10. Espíritu de investigación y reflexión.

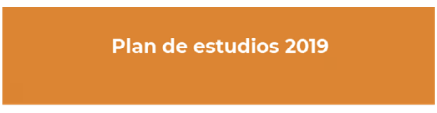

1. Comunicación fluida, efectiva y adecuada. 2. Competencia lingüistica intercultural 3. Alfabetizaciónes múltiples, identidades, inclusión, diversidad y disenso, interculturalidad e hibridación.

4. Docente con habilidad de mediador sociocultural.

5. Responsabilidad pedagógica, social y política en la ensenanza

6. Competencia Lingüística, comunicativa, intercultural y crítica en el uso y la enseñanza de la lengua inglesa en diversos géneros y soportes comunicativos.

7. Exploración y recuperación de múltiples identidades y prácticas culturales, discursivas y comunicativas de variados usuarios del idioma inglés.

8. Alfabetización académica, visual, mediática, y digital.

9. Identidades lingüísticas, diversidady variación en las culturas académicas. 10. Los géneros académicos escritos: convenciones, registros, estilo y audiencia. 11. Lenguajes en contextos y en contactos post $y$ descoloniales: hibridación, glocalidad, inclusión, diversidad y disidencia.

12. Reflexión sobre el universo sociocultural que acompana a la lengua inglesa para poder compararlo y contrastarlo con lo propio 13. Competencias múltiples en el idioma inglés a través del conocimiento de sus aspectos formales, pragmáticos, discursivos y sociolingüísticos

14. Consientización metalingüística e intercultural en el uso y la enseñanza del idioma inglés.

15. Reflexión sobre la diversidad sexogenérica y funcional.

16. Enseñanza de las lenguas extranjeras frente a la inclusión y la exclusión social.

17. Perspectiva de género. 
Borgnia, C. A. (2021). Legislación político-lingüística: análisis comparativo del discurso de dos planes de estudios de profesorado de inglés. UCMaule, 67, julio-diciembre, 98-120. DOI: https://doi. org/10.29035/ucmaule.61.98

El perfil del hablante que se gradúa según el Plan 2019 apunta a la utilización del inglés adecuadamente, a los conocimientos sólidos de los distintos aspectos y niveles de la lengua, al igual que el del Plan 1999, pero además, muestra una aspiración a un manejo más sólido de las herramientas digitales, a un fuerte rol como mediador intercultural y a la inclusión social de una amplia gama de personas pertenecientes a distintos grupos históricamente ignorados, como las personas discapacitadas o del colectivo LGBTI La comparación de ambos perfiles visibiliza un rol sociocultural algo más activo para los docentes que completen el grado según el Plan 2019.

\section{Categoría de análisis 2: ideología lingüística, función del inglés y oferta de lenguas extranjeras.}

Trataremos estas tres categorías juntas ya que están estrechamente vinculadas entre sí. En el caso del Plan 1999, se menciona la enseñanza del inglés como lengua extranjera y como segunda lengua. Actualmente, una gran parte de la literatura sobre las funciones de las lenguas hace una diferenciación entre lenguas extranjeras y segundas lenguas en cuanto al ámbito en que los estudiantes aprenden y utilizan el idioma. En Argentina, el inglés cumple generalmente la función de lengua extranjera, a menos que nos refiramos a casos específicos de estudiantes que concurren a escuelas bilingües y provienen de hogares con hablantes de habla inglesa y su socialización, fuera de la escuela, ocurra en inglés.

En el Plan 2019, continúa estando el sintagma "inglés como lengua extranjera", pero se agregan: "lenguaje de comunicación internacional", "lengua franca", "tercer idioma de contacto entre personas que no poseen un idioma en común", "inclusión de lenguas de diásporas, migraciones y descolonización a través del inglés" e "interculturalidad". Claramente, en este paisaje colorido de funciones del inglés se reflejan las posturas inclusivas de la etapa post-liberal y post-colonial, con su impronta intercultural y la función del inglés como agente mediador. También, se esbozan enfoques más neutrales para algunos (Crystal, 1998; Graddol, 2006) y totalizadores para otros (Mufwene, 2009; Phillipson, 2009; Skutnabb-Kangas, 2000) acerca de designaciones como "inglés global" o "inglés internacional".

Del estudio contrastivo de ambos planes, se infiere que el Plan 1999 concibe al inglés todavía como una lengua más asociada a una sociedad con un multilingüismo incipiente y acaso un bilingüismo. Por otro lado, en el caso del Plan 2019, ese desarrollo se encuentra en evolución y permite pensar, a futuro, en una sociedad más pluralista, multilingüe y con hablantes con distintas variedades y grados de adquisición de la 
Borgnia, C. A. (2021). Legislación político-lingüística: análisis comparativo del discurso de dos planes de estudios de profesorado de inglés. UCMaule, 67, julio-diciembre, 98-120. DOI: https://doi. org/10.29035/ucmaule.61.98

lengua, lo que conlleva una visión del inglés que se va alejando lentamente del inglés estándar. Este plan es el que ofrece, a diferencia del anterior, una lengua asiática, el chino. Sin embargo, a pesar de incorporar la prometedora noción de "Argentina del Cono Sur", ese gesto inclusivo no parece concretarse en la oferta de enseñanza de alguna lengua aborigen, que les daría representatividad a las comunidades de los pueblos originarios de América del Sur. La Tabla 2 muestra un resumen comparativo de ideología lingüística, función del inglés y oferta de lengua extranjeras en los Planes 1999-2019.

Tabla 2: Resumen comparativo de ideología lingüística, función del inglés y ofertas de lenguas extranjeras en Planes de Estudios 1999 y 2019.
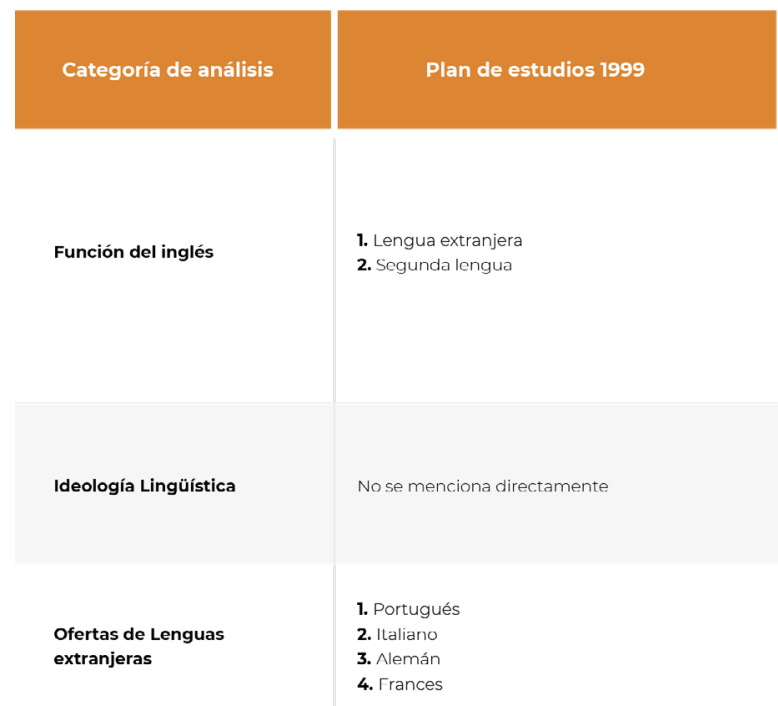

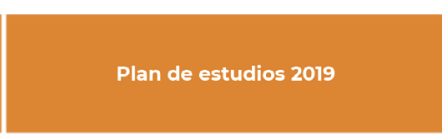

1. Lengua extranjera

2. Lenguaje de comunicación internacional.

3. Lengua franca.

4. Tercer idioma de contacto entre

personas que no poseen un idioma en común.

5. Inclusión de lenguas de diâsporas,

migraciones y descolonización a través

del inglés.

6. Interculturalidad.

1. Plurilingüismo (rechazo de la idea

de una lengua = Estado nación

2. Multilingüísmo.

3. Argentina en el Cono Sur y Sur Global.

\author{
1. Plurilingüismo (rechazo de la idea \\ de una lengua= Estado-nación) \\ 2. Multilingüismo. \\ 3. Argentina en el Cono sur y Sur Global.
}

\section{Categoría de Análisis 3: Sintagmas Usados para Designar Materias de Formación Cultural.}

En el caso de las denominaciones de las materias culturales, que son 5 en cada plan, observamos que ha habido una ampliación de las sociedades cuya historia o literatura se estudia. Mientras que en el Plan 1999, de corte más tradicionalmente anglocéntrico, se ofrece el estudio de la historia/literatura inglesa o estadounidense, en el Plan 2019, se deja al docente a cargo la elección del país/nación/pueblo cuya historia o literatura desee estudiar. Esta propuesta habilita el estudio de los aspectos culturales de países como Sudáfrica, Australia, Jamaica, Escocia, India o Malasia, lo cual muestra un interés por incluir, entre sus metas, el estudio de culturas no hegemónicas. Nos preguntamos ¿qué grado de adhesión a estos cambios tendrán los docentes a cargo de las materias mencionadas? 
Borgnia, C. A. (2021). Legislación político-lingüística: análisis comparativo del discurso de dos planes de estudios de profesorado de inglés. UCMaule, 67, julio-diciembre, 98-120. DOI: https://doi. org/10.29035/ucmaule.61.98

En la Tabla 3 comparamos los sintagmas utilizados para designar las asignaturas de corte cultural en los planes 1999-2019.

Tabla 3: Resumen comparativo de sintagmas utilizados para designar materias culturales en Planes de Estudios 1999 y 2019.
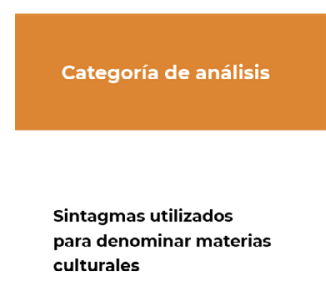
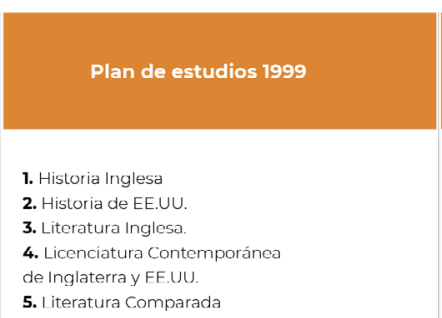

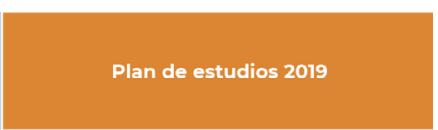

1. Historia de Culturas de Habla Inglesa. 2. Historia Contemporánea de Culturas de habla Inglesa.

3. Literatura en Lengua Inglesa I.

4. Literatura en Lengua Inglesa II.

5. Seminario de literatura comparada

\section{Discusión}

En el presente trabajo hemos realizado un recorrido por las políticas lingüísticas que han operado en Argentina en relación a la enseñanza del inglés como lengua extranjera y hemos analizado y comparado dos planes de estudios en busca de ideologías y representaciones lingüísticas. Revisamos la historia del Profesorado de Inglés y el contexto sociopolítico en el que surgieron los documentos mencionados. También, hemos explorado la legislación lingüística escolar que ha incidido en la enseñanza del inglés y las herramientas teóricas afincadas en la sociología del lenguaje para darle operatividad a nuestro proyecto. Finalmente, realizamos el estudio contrastivo con metodología de análisis del discurso y volcamos los resultados en tablas que nos han permitido sistematizar y explicar los hallazgos.

Con respecto al perfil del docente/hablante de inglés, hay algunas similitudes entre ellos así como indicios en el Plan 1999 que presagian un cambio significativo a concretarse con el Plan 2019. Por ejemplo, ambos planes aspiran a formar un docente comprometido con el entorno sociocultural, reflexivo y con un manejo óptimo de la lengua. Sin embargo, mientras que el Plan 1999 alude más fuertemente a los estereotipos asociados a la clase privilegiada, a los hablantes nativos y al modelo de corrección lingüística, el Plan 2019 amplía el modelo de docente de inglés. El nuevo perfil apunta, de manera más marcada que el 1999, a un hablante que posee una alta competencia comunicativa, discursiva, intercultural y tecnológica. Sin embargo, el cambio más marcado entre ambos perfiles radica en el acento en la perspectiva de género. 
Borgnia, C. A. (2021). Legislación político-lingüística: análisis comparativo del discurso de dos planes de estudios de profesorado de inglés. UCMaule, 67, julio-diciembre, 98-120. DOI: https://doi. org/10.29035/ucmaule.61.98

En cuanto a la categoría de ideologías lingüísticas, funciones del inglés y oferta de lenguas extranjeras, hemos interpretado los hallazgos en base al multilingüismo (social) y al plurilingüismo (individual). En el Plan 1999 se hace mención al inglés como lengua extranjera y como segunda lengua. Tenemos ciertas dudas con respecto a esta última conceptualización y a cómo se llevaría a cabo en Argentina. La idea del inglés como lengua extranjera, que también se menciona en el Plan 2019, es compatible con la ideología del multilingüismo.

Como hemos visto, mediante la legislación educativa nacional, en lo que atañe a las lenguas extranjeras en los últimos años, se ha extendido, ampliamente, la enseñanza del inglés, a expensas de otras lenguas europeas, como el alemán, el italiano y el portugués y se ha proclamado el multilingüismo y el bilingüismo, en el caso de los aborígenes y los Iusoparlantes, ya que ayudaría a fortalecer los lazos con países de la región. No todas estas políticas han sido concretadas, en la misma medida, en los dos planes de estudios analizados. Desafortunadamente, los proyectos de la Educación Intercultural Bilingüe no han sido exitosos en el sistema escolar de la mayoría de las provincias y tampoco hemos visto más que reverberaciones de ellos en los discursos de los planes.

En un país en el que se sigue hablando un gran número de lenguas aborígenes, aunque por grupos no tan numerosos, sorprende que no se visibilicen gestiones para vitalizarlas, atendiendo a las agendas de protección del derecho de los aborígenes a hablar la lengua de identidad. Ninguno de los dos documentos incluye una lengua aborigen en la oferta de lenguas extranjeras. Con respecto a la ideología del eurocentrismo, vemos una apertura en el Plan 2019, en el cual se ofrece una lengua asiática por primera vez dentro del Profesorado, mientras que solo se han ofrecido lenguas europeas hasta el presente. El nuevo plan incluye, entre sus intereses, a los hablantes de distintas diásporas, de territorios poscoloniales y de distintas disidencias y potencia el valor del inglés como lengua que opera interculturalmente.

Finalmente, hemos visto que, en los dos planes, se aborda el estudio de las materias culturales desde perspectivas opuestas. Mientras que el Plan 1999 ofrece materias desde una perspectiva angloamericana, la nueva propuesta presenta materias que se enfocan en pueblos anglófonos no definidos, lo cual posibilita el abordaje del estudio de sociedades de las diásporas, del Caribe, o de los continentes asiático o africano, por ejemplo. Este desplazamiento de las hegemonías vinculadas a los Estados Unidosy Gran Bretaña convoca — desde la currículo oficial y obligatoria-, al encuentro con culturas Otras, las cuales usualmente se estudian en materias opcionales o en seminarios de posgrado. De esta manera, si se logran concretar estas políticas inclusivas en el aula, las 
Borgnia, C. A. (2021). Legislación político-lingüística: análisis comparativo del discurso de dos planes de estudios de profesorado de inglés. UCMaule, 67, julio-diciembre, 98-120. DOI: https://doi. org/10.29035/ucmaule.61.98

posiciones que antes se identificaban con lo hegemónico, se correrían a los bordes, y quienes se identificaban con los márgenes, tendrían acceso al centro. Seguramente, el abordaje de las materias culturales — bajo este nuevo paradigma— contribuirá a romper los estereotipos acerca de la lengua y sus hablantes.

\section{Conclución}

En este trabajo, desde el encuadre de la sociología del lenguaje, hemos escrutado la forma en que desde la legislación nacional, provincial y a nivel local e institucional (UNMDP), se han concretado posicionamientos ideológicos que legitiman y así perpetúan o bien cuestionan el valor del inglés como lengua extranjera en dos planes de estudios de Profesorado de Inglés. A su vez, este estudio también contribuye al campo científico al ser un ejercicio de comparación documental con metodología de análisis del discurso. En resumen, podemos afirmar que uno de los grandes rasgos de la política lingüística argentina respecto del inglés como lengua extranjera en los últimos años ha sido el acento en la inclusión social. A pesar de que las distintas leyes formalizaron un desplazamiento de otras lenguas extranjeras a favor del inglés, es innegable que, en el presente, todos los estudiantes argentinos tienen garantizado el acceso a conocimientos de una lengua extranjera dentro de la escuela, aunque sea el inglés, una lengua vista por muchos como la lengua del imperio. En el pasado, quienes cursaban sus estudios en escuelas del Estado, solo aprendían una lengua distinta de la propia si asistían a institutos privados o tomaban clases particulares. En términos de inclusión, mientras que el Plan 1999 muestra un gesto esperanzador, el Plan 2019 refleja una agenda más inclusiva, al menos al ingreso a la carrera. A pesar de este cambio aparente hacia la inclusión que promovería el acceso a la cultura letrada en inglés para miembros de las clases sociales desfavorecidas, cabe preguntarse si, a largo plazo, el ingresar con más facilidad al Profesorado redundará en un alto índice de egresos o si, por el contrario, el no contar con conocimientos sólidos al comenzar la carrera, devenga en un desempeño transversal pobre o en un futuro desgranamiento en la matrícula. Si la propuesta es que el acceso al dominio del inglés deje de reflejar profundas diferencias sociales, sería deseable que, en un futuro, los planes, además de expresar que todos los argentinos tienen derecho a comunicarse en inglés, no oculten que continúa siendo necesario sostener y, al mismo tiempo, profundizar el aprendizaje del inglés, ya que inevitablemente el dominio de la variedad estándar está fuertemente relacionado con posiciones de privilegio. Finalmente, dado que los planes de estudios de carreras de formación docente en lenguas canalizan intervenciones sociales, económicas y políticas, además de educativas, la omisión de lenguas aborígenes en los programas acentúa dialécticamente su debilitamiento. 
Borgnia, C. A. (2021). Legislación político-lingüística: análisis comparativo del discurso de dos planes de estudios de profesorado de inglés. UCMaule, 67, julio-diciembre, 98-120. DOI: https://doi. org/10.29035/ucmaule.61.98

\section{REFERENCIAS BIBLIOGRÁFICAS}

Arnoux, E. y Del Valle, J. (2010). Las representaciones ideológicas del lenguaje. Discurso glotopolítico y panhispanismo. Spanish in Context, 7, 1, 1-25. http://doi. org/10.1075/sic.7.1.01nar

Arnoux, E. (2000). La Glotopolítica: transformaciones de un campo disciplinario. Lenguajes: teorías y prácticas (pp. 1-15) Gobierno de la Ciudad de Buenos Aires, Instituto Superior del Profesorado.

Arnoux, E. (2006). Análisis del discurso: Modos de abordar materiales de archivo. Homo Sapiens.

Arnoux, E. y Bein, R. (2015). Hacia una historización de las políticas de enseñanza de lenguas. En Arnoux, E. y Bein, R. (Ed.). Política lingüística y enseñanza de lenguas. pp. (1-28). Biblos.

Bein, R. (2004). La legislación político-lingüística en la Argentina. En G. Kremnitz y J. Born. (Ed.). Lenguas, literaturas y sociedad en la Argentina, (pp. 41-50). Praesens.

Bein, R. (2005). Las lenguas como fetiche. En Panesi, J. y Santos, S. (Ed.). Debates actuales: las teorías críticas de la literatura y la lingüística (pp. 4-6). Facultad de Filosofía y Letras, Universidad de Buenos Aires.

Bein, R. (2012a). Argentinos, esencialmente europeos... La influencia de las representaciones en la política lingüística. Quaderna, 1, 1-17. http://quaderna.org/argentinosesencialmente-europeos

Bein, R. (2012b). La política lingüística argentina con relación a las lenguas extranjeras a partir de 1993 [Tesis doctoral, Universität Wien]. http://othes.univie. ac.at/18168/1/2012--01_0868071.pdf

Bein, R. (2015). Legislación sobre lenguas en la Argentina. Manual para docentes. http://www.linguasur.com.ar/manual/

Bein, R. y Varela, L. (2005). El discurso acerca de las lenguas extranjeras en dos momentos de la legislación escolar argentina: 1904 y 1994. Lenguas Vivas, 5, 35-40.

Bourdieu, P. (1997). Razones prácticas. Sobre la teoría de la acción. Barcelona: Anagrama. 
Borgnia, C. A. (2021). Legislación político-lingüística: análisis comparativo del discurso de dos planes de estudios de profesorado de inglés. UCMaule, 67, julio-diciembre, 98-120. DOI: https://doi. org/10.29035/ucmaule.61.98

Cazorla, M. A. (2018). Las diferencias ideológicas sobre la posición dominante del inglés en el ámbito de la globalización en el siglo XXI. Del Prudente Saber y El Máximo Posible De Sabor, 10, 13-37. http://rct.fcedu.uner.edu.ar/index.php/ prudente/article/view/79

Calvet, J-M. (1997). Las políticas lingüísticas. (Trad. L. Varela). Edicial.

Coll, C. (1991). Psicología y curriculum. Grupo Planeta.

Crystal, D. (1998). English as a Global Language. Cambridge University Press.

Fishman, J. A. (1972). Readings in the Sociology of Language. The Hague: Mouton.

Graddol, D. (2006). English Next. Why global English may mean the end of 'English as a Foreign Language'. Language Problems and Language Planning, 32, 203207. https://doi.org/10.1075/lplp.32.2.08amm

Montserrat, M.; Mórtola, G. (2018). La enseñanza del inglés para las grandes mayorías nacionales en Argentina. Revista Digital de Políticas Lingüísticas, 10, vol. 10, 167-19 https://revistas.unc.edu.ar/index.php/RDPL/article/view/22198

Mufwene, S. (2009). Globalization, Global English, and World Englishes: Myths and Fact. En Coupland, N. (Ed), The Handbook of Language and Globalization, (pp. 3155). Blackwell.

Phillipson, R. (2009). Linguistic Imperialism Continued. Orient BlackSwan.

Price, G. (1984). The Language of Britain. London: Edward Arnold.

Ninyoles, R. L. (1972). Fragmentos de Idioma y poder social. En Bein, R. (Ed.). Cuadernos de Glotopolítica 2 (pp. 37-41). Universidad de Buenos Aires.

Skutnabb_Kangas, T. (2000). Linguistic Genocide in Education or Worldwide Diversity and Human Rights? New York: Routledge. 
Borgnia, C. A. (2021). Legislación político-lingüística: análisis comparativo del discurso de dos planes de estudios de profesorado de inglés. UCMaule, 67, julio-diciembre, 98-120. DOI: https://doi. org/10.29035/ucmaule.61.98

\section{DOCUMENTOS OFICIALES CONSULTADOS}

Consejo Federal de Educación NAP (2012). Núcleos de aprendizaje prioritarios. Lenguas extranjeras. Educación primaria y secundaria. Ministerio de Educación.

Dirección Nacional de Migraciones (2008). Inmigración 1857-7920. Ministerio del Interior de la República Argentina

Ley Nacional 24.468 de 2008. 16 de enero de 2009.

Ley de Educación Nacional 26.206 de 2016. 14 de diciembre de 2016.

Asociación Nacional de Facultades de Humanidades y Letras (2015). Lineamientos

Preliminares para los Profesorados Universitarios en Lenguas Extranjeras. http:// www.anfhe.org.ar/archivos/documentos/LETRAS_Lineamientos_presentaci\%F3n_CIN_ junio_2014.pdf

Ordenanza de Consejo Académico de 2011 [Universidad Nacional de Mar del Plata]. 31 de octubre de 2011.

Ordenanza de Consejo Académico de nº803 2013 [Universidad Nacional de Mar del Plata]. 18 de febrero de 2013.

Departamento de Lenguas Moderndas, Universidad Nacional de Mar del Plata (2019). Plan de Estudios del Profesorado de Inglés de la Universidad Nacional de Mar del Plata. https://humanidades.mdp.edu.ar/lenguasmodernas/profingles/ 